\title{
Constitutional Growth Delay Pattern of Growth in Velo-Cardio-Facial Syndrome: Longitudinal follow up and final height of two cases
}

\author{
Serap Turan ${ }^{1}$, Nihal Özdemir ${ }^{1}$, Tülay Güran ${ }^{1}$, Figen Akalın², Teoman Akçay ${ }^{1}$, Canan Ayabakan², \\ Yüksel Yılmaz ${ }^{3}$, Abdullah Bereket ${ }^{1}$ \\ ${ }^{1}$ Marmara University, Department of Pediatric Endocrinology, Istanbul, Turkey \\ ${ }^{2}$ Marmara University, Department of Cardiology, Istanbul, Turkey \\ ${ }^{3}$ Marmara University, Department of Neurology, Istanbul, Turkey
}

Keywords:
Velo-cardio-facial syndrome,
22q11.2, growth, short
stature, growth hormone
deficiency, normal genotype
Received: August 5, 2008
Accepted: August 25, 2008
Corresponding Author:
Serap Turan
Marmara Üniversitesi Tip
Fakültesi Hastanesi Çocuk
Sağlığ1 ve Hastalıkları AD
Tophanelioğlu Cad.
Altunizade Üsküdar-
İstanbul-Turkey
Tel: +90-216 3271010
Fax: +90-216 3250325
E-mail:
serapdemircioglu@yahoo.com

CASE REPORT

\section{ABSTRACT}

We report two patients with velo-cardio-facial syndrome (VCFS) who were admitted to our pediatric endocrinology clinic because of short stature and followed longitudinally until attainment of final height. Both patients followed a growth pattern consistent with constitutional delay of puberty with normal and near normal final height. Case 2 also had partial growth hormone $(\mathrm{GH})$ deficiency and severe short stature (height SDS -3.4 SDS), but showed spontaneous catch-up and ended up with a final height of -2 SDS. These cases suggest that short stature in children with VCFS is due to a pattern of growth similar to that observed in constitutional delay of growth and puberty.

Conflict of interest: None declared

\section{INTRODUCTION}

Velo-cardio-facial syndrome (VCFS) is characterized by a typical facial appearance, learning disabilities, congenital heart defects, hypernasal speech, cleft palate, short stature and transient neonatal hypocalcemia. It was first described by Shprintzen et al(1) in 1978 as a distinct multiple anomaly syndrome. The specific genetic cause of VCFS is a deletion in the long arm of chromosome 22 at the q11.2 band. $(2,3)$ Distal deletion of $4 \mathrm{q}$ and partial monosomy $10 \mathrm{p}$ has also been reported to cause a syndrome similar to VCFS. $(4,5)$ However, genetic defects could not be detected by fluorescence in situ hybridiza- tion (FISH) analysis in 10\% of VCFS cases. $(6,7,8,9,10,11,12)$ A spectrum of phenotypes, often collectively called CATCH22 (cardiac defect, anomaly of face, cleft palate, hypoparathyroidism), is associated with heterozygous deletions of chromosome 22q11.2. This spectrum includes the overlapping entities, DiGeorge malformation complex, VCFS, conotruncal anomaly face syndrome, and isolated outflow tract defect of the heart (conotruncal heart defect: tetralogy of Fallot, truncus arteriosus, and interrupted aortic arch).

Postnatal growth deficiency and short stature are common features of VCFS reported in $36 \%$ to $67 \%$ of the patients. $(13,14,15$, $16,17,18,19,20)$ All patients with 22q11.2 
deletion having short stature reported in a recent study were younger than 10 years of age.(21) On the other hand, only 10\% of adult patients are reported to be below normal height.(13) These observations suggest that short stature in VCFS could be attributable to a growth pattern similar to constitutional delay. To our knowledge, there are no longitudinal studies describing the pattern of growth in patients with VCFS. Furthermore, partial growth hormone deficiency has been detected in 4 patients with 22q11.2 deletion.(22)

Here we report longitudinal growth data of two patients with VCFS and short stature who were followed until attainment of final height.

Figure 1: Facial appearance showing prominent nasal root, malar hypoplasia, long face, narrow palpebral fissures of case 1 (1a) and, depressed nasal bridge, hypoplastic ala nasi, long filtrum, long face, narrow palpebral fissures, hypertelorism and slender fingers of case 2 (1b).
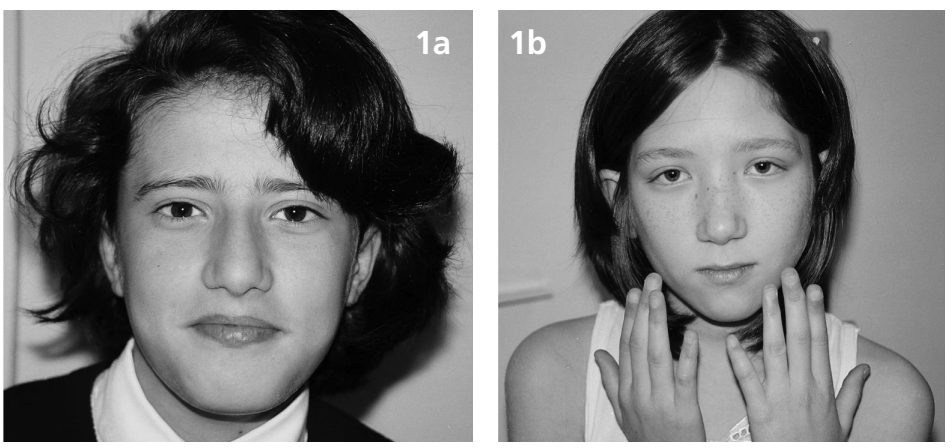

Figure 2: 22q11.2 deletion on FISH analysis of case 2.

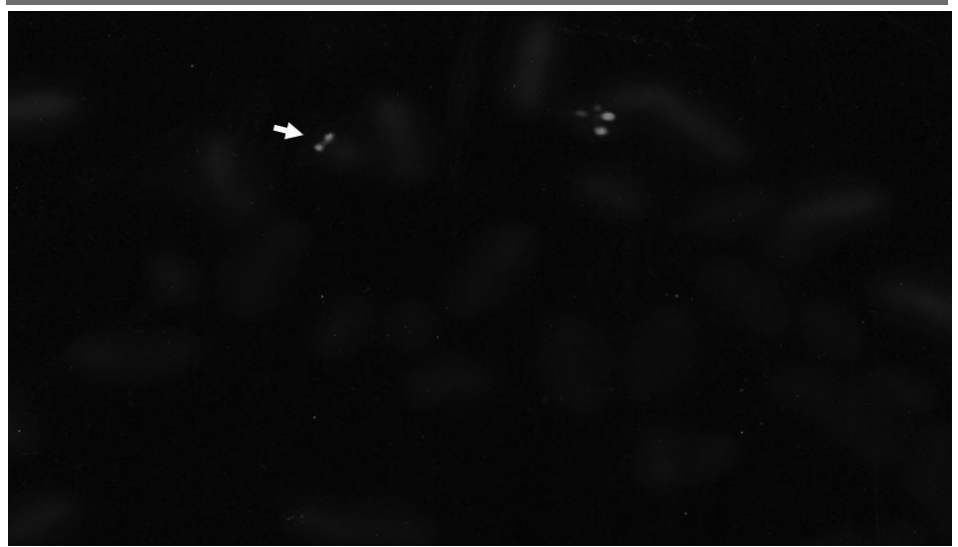

\section{CASE REPORTS}

\section{Case 1}

This female patient was the first child of healthy, non-consanguineous parents. She was born at term after an uneventful pregnancy with a birth weight of 2800 g. At age 3 years she had an operation for club foot. At age 11 years and 4 months she was admitted to our hospital with epileptic seizure. Her weight was $28 \mathrm{~kg}$ and her height was $138 \mathrm{~cm}$ (-2 SDS and -1.9 SDS respectively by national standards). Her bone age was 9 years and 3 months (Greulich Pyle method). Midparental (target) height was $161 \mathrm{~cm}$ (+0.2 SDS). On physical examination she had a prominent nasal root, malar hypoplasia, long face, narrow palpebral fissures, high arched palate, long and slender fingers, scoliosis and umbilical hernia (Figure 1a). Hypernasal speech was noted. The diagnosis of hypoparathyroidism was made on follow-up, based on the low calcium (7.1 mg/dL), high phosphorus (6.2 $\mathrm{mg} / \mathrm{dl}$ ) and inappropriately low parathyroid hormone $(32.5 \mathrm{pg} / \mathrm{mL})$ levels. The typical facial appearance of the patient and her hypoparathyroid state led us to consider VCFS. Chromosome 22q11.2 deletion was demonstrated by FISH analysis using the specific DNA probe (Figure 2). However, it has not been possible to perform a parental FISH analysis in this particular case. Echocardiography demonstrated atrial septal defect. Conductive type hearing loss was detected on the audiogram. WISC-R score was $66 \mathrm{IQ}$. The lymphocyte subset analysis and serum immunoglobulin levels were normal. Renal ultrasound and thyroid functions were also normal. Basal ganglia calcification was not detected on cranial tomography. At follow-up, catch-up growth was noted during puberty (Figure 3). She had menarche at age of 15.5 years. The patient's final height and weight measurements were $159.3 \mathrm{~cm}$ (-0.1 SDS) and $50.8 \mathrm{~kg}$ (-0.8 SDS) respectively at age 18 years and consistent with her target height which was $161 \mathrm{~cm}$ (+0.2 SDS). 


\section{Case 2}

A 13 year-old girl was referred to our pediatric endocrinology clinic for evaluation of short stature. Parents were first cousins. She was born at term by vaginal delivery with a birth weight of $2100 \mathrm{~g}$. At age 11.5 years she had a tonsillectomy/ adenoidectomy operation because of recurrent otitis media. She had learning disabilities especially in mathematics at school and was reported to have attention deficit hyperactivity disorder. She also had decreased visual sharpness. On physical examination her height was $135.8 \mathrm{~cm}(-3.4$ SDS), her weight was $27.7 \mathrm{~kg}$ (-2.3 SDS) while her midparental (target) height was $153.2 \mathrm{~cm}$ (-1.2 SDS). Her bone age corresponded to 10 years (Greulich Pyle method) at the chronological age of 13 years. She had a depressed nasal bridge, hypoplastic ala nasi, long filtrum, long face, narrow palpebral fissures, hyperteleorism, high arched palate and slender fingers (Figure 1b). A high grade systolic ejection murmur was heard on the left sternal border and echocardiography revealed coarctation of aorta and double aortic arch. Small optic discs and tortuous retinal vessels were demonstrated on ophthalmologic examination. WISC-R score was 42 IQ. Diagnosis of VCFS was considered. However, no deletion in the 22q11.2 region was found by FISH and high resolution karyotype analysis was normal. The patient did not have a history of recurrent infections other than otitis media. She had normal serum calcium levels and thyroid hormone levels. A growth hormone (GH) provocative test by clonidine revealed partial GH deficiency (peak GH 6.5 ng/ml). The patient was lost to follow up for 3 years. She had undergone a cardiac operation in this time period. Her menarche had occurred at age of 14 . Her serum insulin like growth factor I (IGF-I) and IGF binding protein 3 (IGFBP-3) levels were 188 and $3770 \mathrm{ng} / \mathrm{mL}$ respectively and below -2 SDS for her age. The patient's final height
Figure 3: Growth chart of case 1 and 2 demonstrating growth pattern typical for constitutional delay of growth (Circles; case 1 , squares; case 2 ).

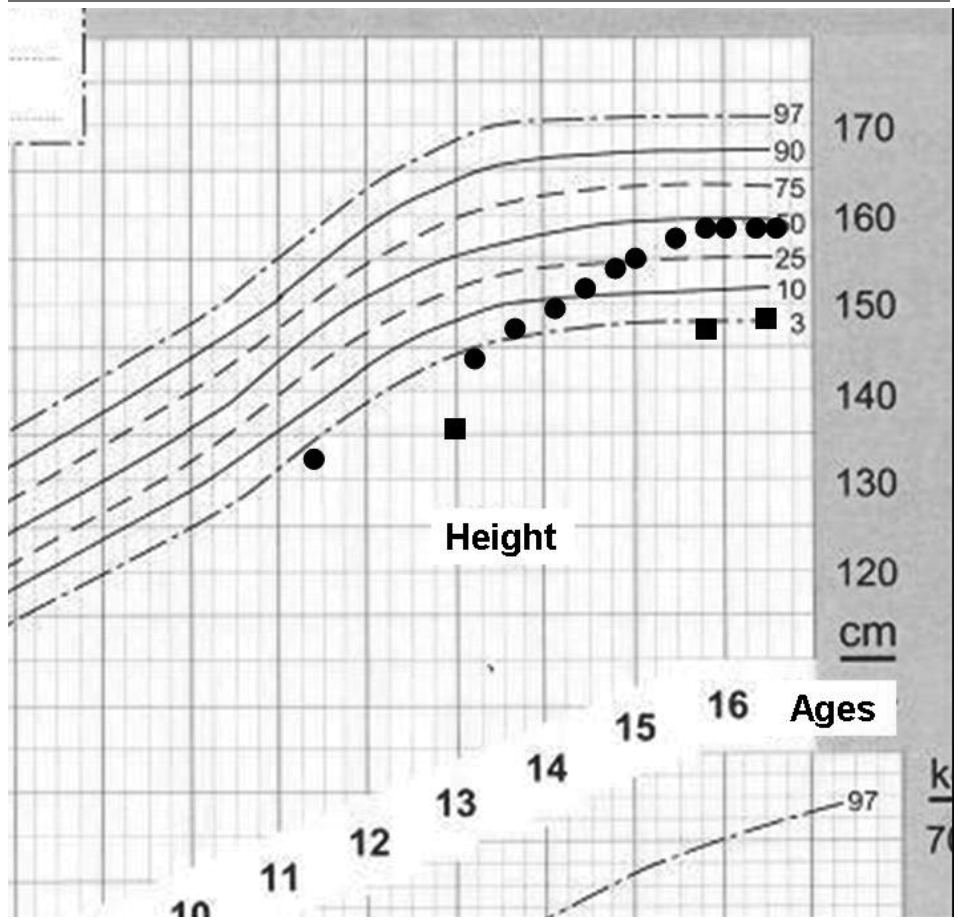

at 16.5 years was $148.3 \mathrm{~cm}(-2.0$ SDS $), 0.8$ SDS lower than her target height. However, a second growth hormone stimulation test with L-Dopa performed at this time revealed showed a normal peak serum $\mathrm{GH}$ level $(11.7 \mathrm{ng} / \mathrm{ml})$.

\section{DISCUSSION}

VCFS is a genetic syndrome with a wide range of clinical features. We report two female patients aged 11 and 13 years presenting to our pediatric endocrinology clinic, one with hypocalcaemia and short stature and, one with short stature and a severe heart defect. The facial appearance (Fig. 1a and 1b) and clinical features of these patients led us to a consider a tentative diagnosis of VCFS.

The growth pattern, age of menarche and final height of these two cases with VCFS were consistent with the pattern of growth of children with constitutional 
delay of growth and puberty as shown in Figure 3. Patient 1 had a satisfactory catchup growth after puberty with a final height consistent with her midparental target height. The second patient demonstrated severe short stature at presentation and also had partial GH deficiency in the first GH stimulation test.However, she demonstrated spontaneous improvement in height after puberty, suggesting that she also had a similar pattern of growth. Despite spontaneous improvement in her height SDS, this patient ended up with a short final height due possibly to intrauterine growth retardation, transient partial GH deficiency or cardiac defect.

Short stature is a frequent finding in VCFS and has been reported to occur in 36\% to $67 \%$ of these patients. $(13,14,15,16,17,18$, $19,20)$ It was postulated to be due to intrauterine growth retardation, feeding difficulties and congenital heart defects. However, no difference in the frequency of short stature was observed in children with/or without cleft palate or congenital heart defect in VCFS (21). Patient series demonstrated that all patients with $22 \mathrm{q} .11 .2$ deletion and short stature were younger than 10 years of age (21), but only $10 \%$ of the adult patients were short (13). This pattern of growth is suggestive of constitutional delay growth pattern. However, in the literature available to us, we did not encounter any longitudinal growth data regarding the growth pattern of patients with VCFS. It is noteworthy that both of our patients showed growth and pubertal patterns typical for constitutional delay of growth and puberty.

Four patients with 22q11.2 deletion and short stature were described to have partial GH deficiency and abnormalities in IGFI.(22) All these cases had heights lower than
-2 SDS and they all benefited from GH treatment. Our second case had severe short stature (-3.4 SDS in height) and failed in the first GH testing. However, she also showed an improvement in her height SDS after puberty and a repeat GH testing showed normal GH response to stimulation, suggesting that GH deficiency was secondary to a constitutional delay of growth and puberty. It is well known that children with constitutional delay of growth and puberty may exhibit transient GH insufficiency due to lack of priming effect of sex steroids on pituitary GH secretion.(23, 24, 25)

In our second case, short stature led to the diagnosis of VCFS with the help of additional findings which consisted of conotruncal cardiac defect, high arched palate, learning disabilities, attention deficit hyperactivity disorder, and ocular findings. Although the clinical findings are consistent with VCFS, we have not detected 22q11.2 deletion or any chromosomal anomaly in this patient. This may be due to the fact that deletion of $22 \mathrm{q} 11.2$ region is not detectable by extensive FISH analysis in approximately $10 \%$ of patients who are clinically diagnosed as 22q11.2 deletion and our patient may have been in this 10\% group.(6, 7, 8, 9, 10, 11, 12) Another possibility in this patient could be an autosomal recessive mutation causing VCFS phenotype due to parental consanguinity.

In conclusion, the longitudinal evaluation of these two patients provide a first demonstration of a growth pattern in VCFS which is consistent with a pattern of growth typical for constitutional delay in growth and puberty. We suggest that $\mathrm{GH}$ stimulation tests in VCFS children should be reserved to those with height deficits exceeding -2SD of their target height.

\section{REFERENCES}

1. Shprintzen RJ, Goldberg RB, Lewin ML, Sidoti EJ, Berkman MD, Argamaso RV, Young D. A new syndrome involving cleft palate, cardiac anomalies, typical facies, and learning disabilities: velo-cardiofacial syndrome. Cleft Palate J 1978; 15:56-62. [Abstract] 
2. Scambler PJ, Kelly D, Lindsay E, Williamson R, Goldberg R, Shprintzen R, Wilson DI, Goodship JA, Cross IE, Burn J. Velo-cardio-facial syndrome associated with chromosome 22 deletions encompassing the DiGeorge locus. Lancet 1992; 339:1138-1139. [Abstract]

3. Carlson C, Sirotkin H, Pandita R, Goldberg R, McKie J, Wadey R, Patanjali SR, Weissman SM, Anyane-Yeboa K, Warburton D, Scambler P, Shprintzen R, Kucherlapati R, Morrow BE. Molecular definition of 22q11 deletions in 151 velo-cardio-facial syndrome patients. Am J Hum Genet 1997; 61:620-629. [Abstract]

4. Tsai CH, Van Dyke DL, Feldman GL. Child with velocardiofacial syndrome and del (4)(q34.2): another critical region associated with a velocardiofacial syndrome-like phenotype. Am J Med Genet 1999; 82:336-339. [Abstract]

5. Daw SC, Taylor C, Kraman M, Call K, Mao J, Schuffenhauer S, Meitinger T, Lipson T, Goodship J, Scambler P. A common region of $10 p$ deleted in DiGeorge and velocardiofacial syndromes. Nat Genet 1996; 13:458-460. [Abstract / PDF]

6. Novelli G, Amati F, Dallapiccola B. UFD1L and CDC45L: a role in DiGeorge syndrome and related phenotypes? Trends Genet 1999; 15:251-254. [Abstract / Full Text / PDF]

7. Yamagishi H, Garg V, Matsuoka R, Thomas T, Srivastava D. A molecular pathway revealing a genetic basis for human cardiac and craniofacial defects. Science 1999; 283:1158-1161. [Abstract]

8. Levy A, Demczuk S, Aurias A, Depetris D, Mattei MG, Philip N. Interstitial 22q11 microdeletion excludingt he ADU breakpoint in a patient with DiGeorge syndrome. Hum Mol Genet 1995; 4:2417-2419. [Abstract / PDF]

9. McQuade L, Christodoulou J, Budarf M, Sachdev R, Wilson M, Emanuel B, Colley A. Patient with a $22 q 11.2$ deletion with no overlap of the minimal DiGeorge syndrome critical region (MDGCR). Am J Med Genet 1999; 86:27-33. [Abstract / Full Text]

10. O'Donnell H, McKeown C, Gould C, Morrow B, Scambler P. Detection of an atypical 22q11 deletion that has no overlap with the DiGeorge syndrome critical region. Am J Hum Genet 1997; 60:1544-1548. [Abstract]

11. Kurahashi H, Nakayama T, Osugi Y, Tsuda E, Masuno M, Imaizumi K, Kamiya T, Sano T, Okada S, Nishisho I. Deletion mapping of 22q11 in CATCH22 syndrome: identification of a second critical region. Am J Hum Genet 1996; 58:1377-1381. [Abstract]

12. Saitta SC, McGrath JM, Mensch H, Shaikh TH, Zackai EH, Emanuel BS. A 22q11.2 deletion that excludes UFD1L and CDC45L in a patient with conotruncal and craniofacial defects. Am J Hum Genet 1999; 65:562-566. [Abstract]

13. Young D, Shprintzen RJ, Goldberg RB. Cardiac malformations in the velocardio-facial syndrome. Am J Cardiol 1980; 46: 643-648. [Abstract]

14. Shprintzen RJ, Goldberg RB, Young D, Wolford L. The velo-cardiofacial syndrome: a clinical and genetic analysis. Pediatrics 1981; 67:167-172. [Abstract / Full Text / PDF]

15. Lipson AH, Yuille D, Angel M, Thompson PG, Vandervoord JG, Beckenham EJ. Velocardiofacial (Shprintzen) syndrome: an important syndrome for the dysmorphologist to recognize. J Med Genet 1991; 28: 596-604. [Abstract]

16. Jedele KB, Michels VV, Puga FJ, Feldt RH. Velo-cardio-facial syndrome associated with ventricular septal defect, pulmonary atresia, and hypoplastic pulmonary arteries. Pediatrics 1992; 89:915-919. [Abstract / PDF]

17. Goldberg R, Motzkin B, Marion R, Scambler PJ, Shprintzen RJ. Velo-cardio-facial syndrome: a review of 120 patients. Am J Med Genet 1993; 45:313-319. [Abstract / Full Text]

18. Motzkin B, Marion R, Goldberg RB, Shprintzen RJ, Saenger P. Variable phenotypes in velocardiofacial syndrome with chromosomal deletion. J Pediatr 1993; 123: 406-410. [Abstract]

19. Seaver LH, Pierpont JW, Erickson RP, Donnerstein RL, Cassidy SB. Pulmonary atresia associated with maternal 22q11.2 deletion: possible parent of origin effect in the conotruncal anomaly face syndrome. J Med Genet 1994; 31:830-834. [Abstract]

20. Ryan AK, Goodship JA, Wilson DI, Philip N, Levy A, Seidel H, Schuffenhauer S, Oechsler H, Belohradsky B, Prieur M, Aurias A, Raymond FL, Clayton-Smith J, Hatchwell E, McKeown C, Beemer FA, Dallapiccola B, Novelli G, Hurst JA, Ignatius J, Green AJ, Winter RM, Brueton L, Brondum-Nielsen K, Stewart F, Van Essen T, Patton M, Paterson J, Scambler PJ. Spectrum of clinical features associated with interstitial chromosome 22q11 deletions: a European collaborative study. J Med Genet 
1997; 34:798-804. [Abstract]

21. Digilio MC, Marino B, Cappa M, Cambiaso P, Giannotti A, Dallapiccola B. Auxological evaluation in patients with DiGeorge/velocardiofacial syndrome (deletion 22q11.2 syndrome). Genet Med 2001; 3:30-33. [Abstract]

22. Weinzimer SA, McDonald-McGinn DM, Driscoll DA, Emanuel BS, Zackai EH, Moshang T Jr. Growth hormone deficiency in patients with 22q11.2 deletion: expanding the phenotype. Pediatrics 1998; 101: 929-932. [Abstract / Full Text / PDF]

23. Gourmelen M, Pham-Huu-Trung MT, Girard F. Transient partial hGH deficiency in prepubertal children with delay of growth. Pediatr Res 1979; 13:221-224. [Abstract]

24. Kastrup KW, Andersen H, Eskildsen PC, Jacobsen BB, Krabbe S, Petersen KE. Combined test of hypothalamic-pituitary function in growth retarded children treated with growth hormone. I. Secretion of growth hormone and somatomedin before and after treatment. Acta Paediatr Scand (Suppl) 1979; 277:8-13. [Abstract / Full Text]

25. Clayton PE, Shalet SM, Price DA. Endocrine manipulation of constitutional delay in growth and puberty. J Endocrinol 1988; 116:321-323. [Abstract / PDF] 